\title{
25 Research Square \\ Experimental evidence for the effect of ELF electric field on prostate cancer cell lines in-vitro
}

\author{
Dariush Sardari \\ Islamic Azad university \\ Iman Momeni \\ Islamic Azad university \\ Sajad Keshavarz ( $\square$ sajadkeshavarz7@gmail.com ) \\ Islamic Azad university https://orcid.org/0000-0003-1103-6810

\section{Leila Anvari} \\ Islamic Azad university \\ Nader Esteeri \\ Islamic Azad university
}

\section{Research article}

Keywords: Prostate cancer, $50 \mathrm{~Hz}$ electric field, cell line, Du-145

Posted Date: August 28th, 2019

DOI: https://doi.org/10.21203/rs.2.10903/v1

License: (c) (i) This work is licensed under a Creative Commons Attribution 4.0 International License. Read Full License 


\section{Abstract}

Background The effect of extremely low frequency electric field on cancer cell proliferation is studied invitro. Methods Prostate cancer cell culture type Du-145 has been grown in the form of spheroids. It is shown that ELF with $50 \mathrm{~Hz}$ frequency is effectively suppressing the growth of spheroids and finally reduces their size. Results It is observed that low voltage low frequency electric filed applied for at least 2 hours a day over one week can stop the growth or even reduce the volume of multi-cellular tumor spheroids significantly. No effect for the case of electric field presence in order of 10 -30 minutes per day has been observed.

\section{Background}

Prostate cancer is the second most common cancer among men bout 1 man in 7 will be diagnosed with prostate cancer during his lifetime can often be treated successfully. About 1 man in 39 will die of prostate cancer. The American Cancer Society's estimates for prostate cancer in the United States for 2016 are about 190,000 new cases of prostate cancer and 26,000 deaths (Siegel, 2016).

Studies on feasibility of prostate cancer treatment with electric field are scarce. Generally, presence of electric field in the cell ambient can disturb the division process (Sardari, 2010). Unlike radiation therapy with X-and gamma ray, electric fields have no side effects on healthy tissues (Koreckij, 2010 and Filipovic 2014). Meanwhile, care must be taken for an adverse effect since the growth of tumor due to excitation by electric field has been reported. It is shown that ELF-EMFs increase cell growth (Eleuteri et al. 2009).

Electric field is mentioned as a cause of living cell necrosis and death (Kamal Hosain et al. 2011 and Kamal Hosain et al. 2012). The interaction of mammalian cells with EM fields varies with the regions of the spectrum in terms of frequency or wavelength. This is due to various kinds of interactions that undermine cell functions (Sadafi et al. 2006). Externally applied Electric and magnetic fields change the physical conditions inside the tissue through its cellular mechanisms that take effect via orientation of molecules, ionic and molecular currents, lifetime of free radicals and temperature of the biological system. This in turn is undermined by physical properties of the incident wave such as frequency, amplitude, wave shape and exposure time which leads to variations in chemical reaction rates, signaling between cells, molecular bindings, and cell growth rates.

At DC electric field, metastatic cell migration has been proven to be an effective way for disturbing cancer cell proliferation in breast and prostate (McCaig et al. 2009). With high intensity low-frequency external electric field, DNA damage is speculated as the cause of cancer cell antiproliferation agent. Evidence has been observed for the effect of extremely low frequency electric field (ELF-EF) on cancer cell of breast, colon and HCT-116 (Filipovic et al. 2014). 
Electric field disturbs ion exchange through cell membrane by varying the electric potential across the cell membrane. This leads to lower interaction for vital enzymes.

Another way for the cell taking destructive effect from alternating electric fields is damage to DNA strands in the course of mitotic cell division. Actually, the non-uniform electric field in the cell junction becomes amplified (Sardari et al. 2010). This mechanism incurs little effect on cells that undergo less frequent divisions, such as normal cells.

In the present work, low frequency $(50 \mathrm{~Hz})$ electric field was applied to cell cultures by electrodes located outside the dish. Since the MTS is the beginning point for cancerous tumor development (Sardari et al. 2009), in the present work the MTS (multi-cellular tumor spheroid) growth was in focus of our attention.

\section{Methods}

Experimental subject was MTS cell lines belonging to Du-145 kind human prostate. The Du- 145 cell culture were provided by Iran University of Medical Science (IUMS). Prostate cancer cells were cultured in proper $\mathrm{pH}$ and temperature. After 20 days, the spheroid diameters grow to 200 microns. All through the experiment cell concentration and size were observed and counted with the use of optical microscope Bell- inverse phase.

Cell line was cultured in an environment with temperature 37 in atmosphere of 5\% CO2 and moisture $95 \%$. It was grown in Petri dishes special for spheroid culture with $100 \mathrm{~mm}^{2}$ area. In this manner, monolayer DU-145 cell culture with $10^{4}$ cell $/ \mathrm{cm}^{2}$ density was prepared and kept till 6 passages. After 20 days of incubation, spheroids continued growth to 200 micrometer diameters. The thickness of solution was $0.5 \mathrm{~cm}$. Then the MTS was let to grow in size for another week as explained below.

The test group suffered electric filed while the control group was kept in the proper growth condition without electric field. The intensity of electric field was $9 \mathrm{~V} / \mathrm{cm}$. The growth curve was plotted for data collected over 7 days. The cell lines were placed in electric filed for 2 hours a day. These data have been the result of three independent repetition of the same experiment.

It was intended to design the electrode setup in a way to produce electric field intensity of $9 \mathrm{~V} / \mathrm{cm}$. for biological environment Platinum (Pt) electrode is desirable due to its biocompatibility but it is expensive. Thus, copper electrode was utilized. Electrode holders were designed and manufactured from Plexiglas so that the distance between electrodes was adjustable from 3 to $12 \mathrm{~cm}$. A transformer wound in our workshop reduced 220 volts from the main to desired low voltage. A 1 Mega-ohm series resistor was included in the circuit to extinguish any possible spark.

Alkaline comet assay method was undertaken to assess DNA damage due to electric field presence in the cell culture.

\section{Results}


The following regions were recognized in the cell population growth curve: 1- lag phase in which cells show delay in growth. 2- log phase in which the growth obeys exponential rule. 3-Plateau phase cell growth is stopped. Doubling time was measured for both MTS population density and MTS volume.

At first, DC electric field provided by a battery proved to make negligible effect on stopping the growth of DU-145 prostate cells. While in presence of electric field of $50 \mathrm{~Hz}$ Spheroid volume became almost half in comparison with the control sample. Extremely low frequency electric field (ELF) has more penetration into the ionized environments such as tissue than fields in $\mathrm{kHz}$ frequency range.

Results are shown in table 1, which along with figure 1 shows the data obtained for the case of electric field for 2 hours per day compared with the control sample of zero electric field (sham). Table 2 contains the doubling time for MTS population as well as its volume doubling time.

Comet assay shows that electric field described above incurs DNA damage to DU-145 cells which are undergoing division process (fig. 2)

\section{Discussion And Conclusions}

Increasing number of prostate cancers is observed in developed societies. Prostate cancer cases have become more than lung cancer recently. Although hormone therapy is a solution to metastatic prostate cancer, alternative modalities is an advantage. Application of electric, magnetic and electromagnetic fields with various frequency ranges for cancer tumor treatment is being developed. Besides theoretical works on modeling the effects of EM fields on cancer cell in general (Sardari et al., 2010; Sadafi et al., 2006; Sardari et al. 2009; Sarbazvatan et al., 2015), in the present work we have carried out in practice an in-vitro model to demonstrate the reduction of growth in prostate tumor volume under the influence of ELF-EF. In-vitro models avoid the complexity of In-vivo experiments and provide a manageable set-up.

It was observed that applied electric field in order of 10 - 30 minutes per day has no effect on stopping spheroid volume growth. Totally, $15 \%$ error was observed in results due to electric field variation and cell growth condition.

Electric field with 9 Volts/cm intensity and $50 \mathrm{~Hz}$ frequency (half-wave rectified from the mains) can stop the growth of Du-145 micro-spheroids size and population.

A constant potential taken from a 9-volt battery to apply electric field to the cell line had no effect in cell culture. This is due to the fact that the cell culture is embedded in ionized medium and a DC electric field cannot penetrate in it.

\section{Abbreviations}

ELF-EF: extremely low frequency electric field; MTS: Multi-cellular Tumor Spheroid; DC: Direct Current; IUMS: Iran University of Medical Science. 


\section{Declarations}

\section{Ethical approval:}

Not applicable

Consent for publication

Not applicable

Availability of data and materials

Funding

None.

\section{Competing Interests}

The authors declare that they have no competing interests.

\section{Availability of data and materials}

Not applicable

\section{Authors' contributions}

All authors read and analyzed the data and writing the manuscript and then approved the final manuscript.

\section{Acknowledgment}

Authors are thankful to Dr. Samideh Khoei for her great help and advices in preparation of cell culture.

\section{References}

Eleuteri, A. M., Amici, M., Bonfili, L., Cecarini, V., Cuccioloni, M., Grimaldi, S., Giuliani, L., Angeletti, M., Fioretti, E. (2009). $50 \mathrm{~Hz}$ extremely low frequency electromagnetic fields enhance protein carbonyl groups content in cancer cells: effects on proteasomal systems. Journal of biomedicine and biotechnology, $2009 ; 84239$.

Filipovic, N., Djukic, T., Radovic M, Cvetkovic, D., Curcic, M., Markovic, S., Peulic , A., Jeremic, B., (2014). Electromagnetic field investigation on different cancer cell lines. Cancer Cell International 14:84. 
Kamal Hosain, M. D., Kouzani, A. Z., Kaynak, A., Lefevre, C., (2011). Electromagnetic Field and other physical methods influencing cell growth in mammal cell culture systems. Proceedings of 2011 IEEE International Conference on Applied Superconductivity and Electromagnetic Devices Sydney, Australia, December 14-16.

Kamal Hosain, M. D., Fateha Samad, M. S. T., Alam, M. S., (2012). Effects of electromagnetic fields on mammalian cells. International journal of electrical and computer engineering (IJECE) 2: 267-276.

Koreckij, T. D., Hill, C., Azure, L. et al. (2010). Low dose alternating current inhibits growth of prostate cancer. The Prostate 70: 529-39.

McCaig, C. D., Song, B., Rajnicek, A. M., (2009). Electrical dimensions in cell science, Journal of cell science. 122: 4267-4276.

Sadafi, H. A., Mahmoodi, Z., Sardari, D., (2006). Modeling biological effects of Extremely low frequency electromagnetic fields. Australasian Physical and Engineering Sciences in Medicine, 29(1): 135.

Sarbazvatan, S., Sardari, D., Taheri, N., Sepanloo, K., (2015). Response of single cell acute angle exposed to an external electric field. Medical Engineering and Physics, 2015; 37(10): 1015-1019.

Sardari, D., Verga, N., Arbabi, A., Ameri, A., Amirifar, S., (2009). Physical modeling of cancer tumor growth: a preliminary review. Australian Journal of Basic and Applied Sciences 3(4): 3531-3536.

Sardari, D., Verga, N., (2010). Calculation of externally applied electric field intensity for disruption of cancer cell proliferation. Electromag. Biol. Med. 29: 26-30.

Siegel, R. L., Miller, K. D., Jemal, A., (2016). Cancer statistics. CA Cancer J Clin., 66: 7-30.

\section{Tables}




\begin{tabular}{|c|c|c|}
\hline day & Volume of control $\times 10^{6}(\mu \mathrm{m})^{3}$ & ${\text { Volume with E field } \times 10^{6}(\mu \mathrm{m})^{3}}$ \\
\hline 0 & 5.98 & 6.1 \\
\hline 1 & 8.13 & 5.65 \\
\hline 2 & 8.95 & 6.65 \\
\hline 3 & 11.4 & 5.82 \\
\hline 4 & 15.8 & 5.02 \\
\hline 5 & 18.6 & 5.65 \\
\hline 7 & 25.7 & 7.02 \\
\hline
\end{tabular}

Table 1- MTS volume in control sample (No electric field) compared with sample kept in electric field for 2 hours a day.

\begin{tabular}{|c|c|}
\hline MTS volume doubling time & 61.5 Hours \\
\hline MTS population doubling time & $38 \pm 0.5$ Hours \\
\hline
\end{tabular}

Table 2- Volume and population doubling time as measured with repeating the same experiment.

\section{Figures}

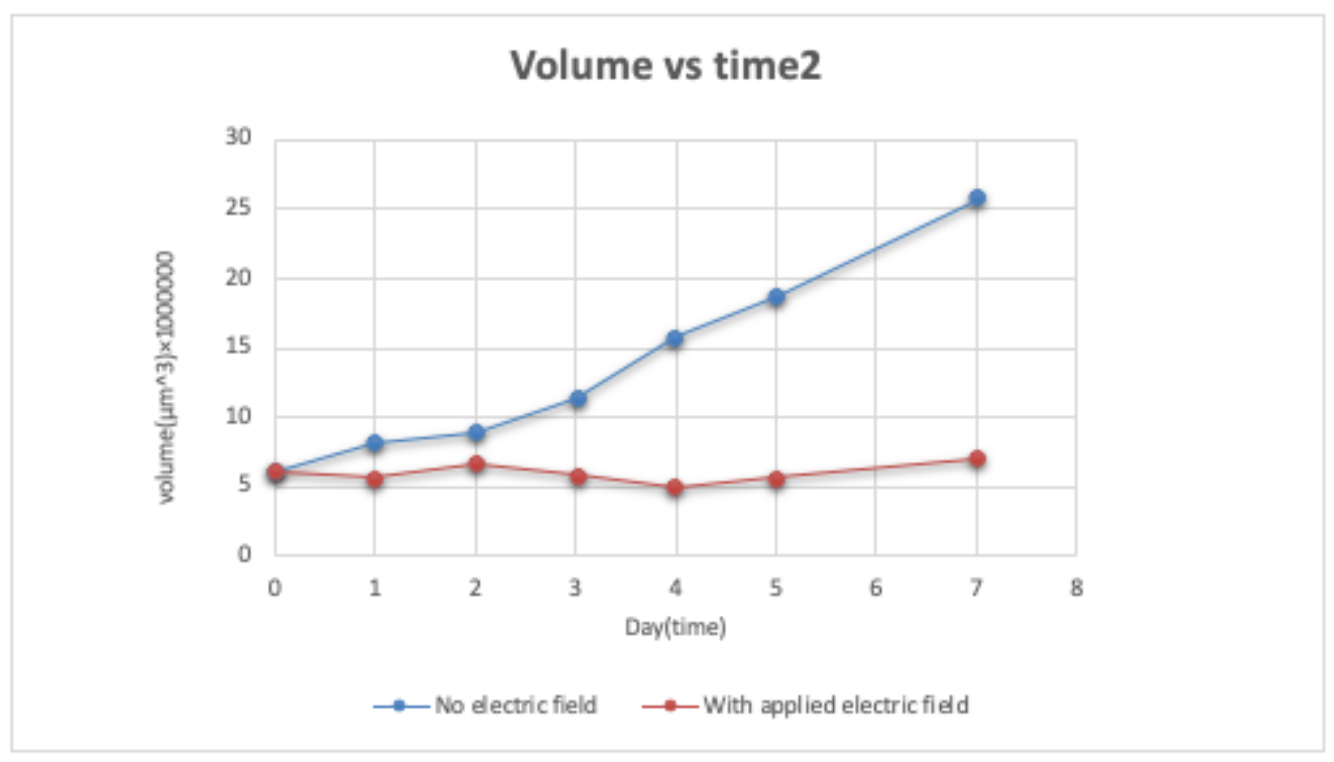

\section{Figure 1}

Variations of MTS volume over 7 days when the electric field was applied for 2 hours per day. 


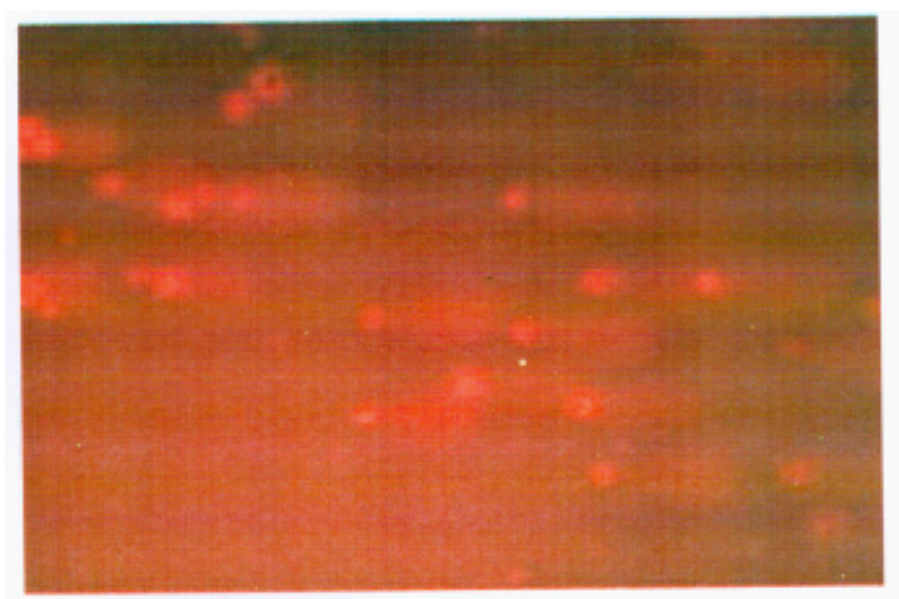

Figure 2

The image registered after comet assay. 